\title{
Experten unter sich: Warum die Regierung findet, dass die Snowden-Affäre uns nichts angeht
}

VB verfassungsblog.de/experten-unter-sich-warum-die-bundesregierung-findet-dass-uns-die-snowden-affarenichts-angeht/

Philip Liste Do 11 Jul 2013

\begin{abstract}
"Vernünftig ist, dass die politischen Spitzen, wenn sie miteinander sprechen, darüber sprechen, wie mit der Sache umzugehen ist, wie ernst Vorwürfe zu nehmen sind und wie man damit umgeht, Vorwürfe zu besprechen, zu klären, zu verifizieren oder aus der Welt zu schaffen. Vernünftig ist, dass über die tatsächliche Art dessen, was nachrichtendienstlich auf der einen oder anderen Seite getan worden ist, diejenigen sprechen, die die intensive Detailkenntnis davon haben" (Regierungssprecher Seibert bei der Bundespressekonferenz in Berlin am 08.07.2013).
\end{abstract}

Ist dieses Statement von Regierungssprecher Seibert einer Demokratie würdig oder finden wir hierin das Manifest einer sich herausbildenden weltstaatlichen Expertokratie? Dies ist eine rhetorische Frage. Bei den sich verdichtenden Anzeichen für eine systematische und vor allem international vernetzte Bespitzelung von Bürgerinnen und Bürgern drängt sich eine Parallele geradezu auf: Anne-Marie Slaughters Überlegungen zu transgouvernementaler Netzwerk-Governance und dem Entwurf einer „Neuen Weltordnung“.

Den Ausgangspunkt dieser vielbeachteten Arbeit bildet die Beobachtung, dass substaatliche Stellen („agencies“) zunehmend über Staatsgrenzen hinweg kooperieren und netzwerkartige Strukturen des Regierens ausbilden. Die internationalen Beziehungen verändern sich dadurch. Es sind nicht mehr nur die Spitzen der Staaten, die auf der diplomatischen Bühne miteinander verhandeln, sondern einzelne Organe der Exekutiven. Die an dieser Exekutivvernetzung beteiligten Akteure bezeichnet Slaughter anschaulich als die „new diplomats“. Doch auch parlamentarische Gremien oder Gerichte bezieht Slaughter in ihre Beobachtung mit ein. Letztere beziehen ausländische Urteile in ihre Rechtsprechung ein, Richter und Richterinnen treffen immer regelmäßiger ihre ausländischen Kollegen und Kolleginnen, usw. Ob hierdurch tatsächlich so etwas wie eine globale Gerichtsgemeinschaft („global community of courts“) - so Slaughters These - entsteht, mag bezweifelt werden und lässt sich demokratietheoretisch kritisieren.

Aber die globale Exekutivvernetzung wiegt schwerer und hinterlässt einen wohl tieferen Abdruck auf der Demokratie - insbesondere dann, wenn sich der so vernetzte Staat systematisch der demokratischen Norm der Transparenz verweigert. Nun lässt sich freilich darüber streiten, ob und inwieweit dem Staat und seinen nun global vernetzten Stellen etwa im Blick auf die Abwehr des Terrorismus ein gewisses Maß an Geheimniskrämerei gestattet werden soll. Wo allerdings vernetztes Regieren in Form von „transgouvernementalen“ Verträgen auf Dauer gestellt wird, geht es um die Form von Staatlichkeit. „Gibt es solche Verträge?“, wollte ein Journalist im Blick auf die Abhörpraxis der NSA bei der oben genannten Pressekonferenz am 08. Juli wissen. „Das müsste doch auch ohne wochenlange Sachaufklärung herauszufinden sein“.

Die Antwort Seiberts hierauf lautete: „Ich dachte, dass ich auch schon gesagt hätte, dass über die Art und Weise sowie auch über mögliche Absprachen bei dieser Zusammenarbeit dem Parlamentarischen Kontrollgremium berichtet wird“. Die Institutionalisierung transgouvernementaler Kooperation und der damit einhergehende Formwandel von Staatlichkeit bleiben also Geheimsache. Die Auswirkungen der "global network governance“ auf den Staat bringt Slaughter auf den Begriff der „disaggregated sovereignty“. Entgegen der verbreiteten Annahme nach der der Staat im Zuge der Globalisierung ins Hintertreffen gerate, lautet die These, dass sich lediglich die Formen des globalen Regierens veränderten, und zwar: mit einem Trend zur transgouvernementalen Vernetzung. 
Auffällig ist dabei, dass Slaughter - selbst für einige Jahre unter Außenministerin Clinton im State Department als Beraterin tätig - die zivilgesellschaftlichen Umwelten staatlichen Regierens ausblendet. In ihrem durchaus auch normativ zu verstehenden Entwurf einer „neuen Weltordnung“ findet die demokratische Öffentlichkeit keinen Platz weder auf nationaler noch globaler Ebene. Zwar verweist Slaughter in ihrem Entwurf auf das Konzept der Gewaltenteilung und deutet damit - mal implizit, mal explizit - an, dass es ihr in erster Linie um die Vernetzung des Regierens liberaler Demokratien geht. Die sonderbare Abwesenheit der Zivilgesellschaft und insbesondere die sich abzeichnende Passgenauigkeit, mit der sich die aktuellen nachrichtendienstlichen Vorgänge in Slaughters Matrix einfügen, nährt indes eine andere These. Es geht hier nicht um eine netzwerkartige Form des demokratischen Regierens unter Bedingungen der Globalisierung, einschließlich der Bedrohungen, die diese mit sich bringt. Wir beobachten vielmehr die Herausbildung einer sich nach und nach akzentuierenden „internationalen Aristokratie“ (Philip Allott). Grenzüberschreitende Behördenvernetzung schafft (noch) keinen Weltstaat. Es lassen sich aber die entsprechenden Netzwerkphänomene als Momente von Weltstaatlichkeit deuten (die Unterscheidung zwischen Weltstaat und Weltstaatlichkeit hat der Bielefelder Politikwissenschaftler Mathias Albert eingeführt) - und diese Momente von Weltstaatlichkeit nehmen deutlich expertokratische Züge an.

Mit Blick auf die Abhörskandale auf den Kalten Krieg zu verweisen (Regierungssprecher Seibert am 1. Juli), ist deshalb irreführend. Die Konfliktlinie verläuft nicht territorial zwischen zwei Staaten oder gar Gesellschaften. Sie verläuft vielmehr zwischen einem global agierenden Behördennetzwerk und der Zivilgesellschaft, die sich insofern gar transnational als eine „Schicksalsgemeinschaft“ fassen ließe, da ja „US-amerikanische“ und „deutsche“ oder „europäische“ Kommunikation gleichsam zum Gegenstand der Spionage geworden zu sein scheint.

In einem Punkt aber hatte Seibert recht: „Abhören von Freunden, das ist inakzeptabel!“ Offenbar fallen Bürgerinnen und Bürger nicht in diese Kategorie. Der Bruch besteht gerade darin, dass der disaggregierte, global vernetzte Staat den Bürgern und Bürgerinnen, unabhängig von ihrem Aufenthaltsort oder ihrer „Staatsangehörigkeit“, zu misstrauen scheint. Jenseits des Regierungsnetzwerks ist der Staatsfeind. Jenseits des Regierungsnetzwerks sind ... wir.

\section{LICENSED UNDER CC BY NC ND}

SUGGESTED CITATION Liste, Philip: Experten unter sich: Warum die Regierung findet, dass die Snowden-Affäre uns nichts angeht, VerfBlog, 2013/7/11, http://verfassungsblog.de/experten-unter-sich-warum-die-bundesregierungfindet-dass-uns-die-snowden-affare-nichts-angeht/. 